\title{
Neural Processes Supporting Young and Older Adults' Emotional Memories
}

\section{Citation}

Kensinger, Elizabeth A., and Daniel L. Schacter. 2008. Neural processes supporting young and older adults' emotional memories. Journal of Cognitive Neuroscience 20, no. 7: 1161-1173.

\section{Published Version}

http://dx.doi.org/10.1162/jocn.2008.20080

\section{Permanent link}

http://nrs.harvard.edu/urn-3:HUL.InstRepos:3199018

\section{Terms of Use}

This article was downloaded from Harvard University's DASH repository, and is made available under the terms and conditions applicable to Other Posted Material, as set forth at http:// nrs.harvard.edu/urn-3:HUL.InstRepos:dash.current.terms-of-use\#LAA

\section{Share Your Story}

The Harvard community has made this article openly available.

Please share how this access benefits you. Submit a story.

\section{Accessibility}




\title{
Neural Processes Supporting Young and Older Adults' Emotional Memories
}

\author{
Elizabeth A. Kensinger ${ }^{1,2}$ and Daniel L. Schacter ${ }^{2,3}$
}

\begin{abstract}
Young and older adults are more likely to remember emotional information than neutral information. The present functional magnetic resonance imaging study examined the neural processes supporting young (ages 18-35) and older (ages 62-79) adults' successful encoding of positive, negative, and neutral objects (e.g., a sundae, a grenade, a canoe). The results revealed general preservation of the emotional memory network across the age groups. Both groups recruited the amygdala and the orbito-frontal cortex during the successful encoding of positive and negative information. Both ages also showed valence-specific recruitment: right fusiform activity was greatest during the successful encoding of negative information, whereas left prefrontal and temporal activity was
\end{abstract}

\section{INTRODUCTION}

Individuals typically are more likely to remember emotional information than they are to remember nonemotional information (LaBar \& Cabeza, 2006; Reisberg \& Heuer, 2004; Buchanan \& Adolphs, 2002). Although the neural processes corresponding to this emotional memory enhancement have been thoroughly studied in young adults, with activation in the amygdala and the orbito-frontal cortex corresponding with later memory for emotional material (LaBar \& Cabeza, 2006; Hamann, 2001), little is known about how the emotional memory network changes with age. The primary goal of the present study was to examine the neural processes that correspond with young and older adults' successful encoding of emotional information.

On the one hand, there is reason to believe that the emotional memory network may be fairly stable with aging. Some behavioral studies have suggested that older adults display emotional memory enhancements comparable to those of young adults (e.g., Denburg, Buchanan, Tranel, \& Adolphs, 2003; Kensinger, Brierley, Medford, Growdon, \& Corkin, 2002). Moreover, the regions associated with emotional memory in young

\footnotetext{
${ }^{1}$ Boston College, ${ }^{2}$ Athinoula A. Martinos Center for Biomedical Imaging, ${ }^{3}$ Harvard University
}

greatest during the successful encoding of positive information. These valence-specific processes are consistent with behavioral evidence that negative information is processed with perceptual detail, whereas positive information is processed at a conceptual or schematic level. The only age differences in emotional memory emerged during the successful encoding of positive items: Older adults showed more activity in the medial prefrontal cortex and along the cingulate gyrus than young adults. Because these regions often are associated with self-referential processing, these results suggest that older adults' mnemonic boost for positive information may stem from an increased tendency to process this information in relation to themselves. adults (e.g., amygdala and orbito-frontal cortex) tend to be relatively preserved with aging, both structurally (Salat et al., 2004; Salat, Kaye, \& Janowsky, 2001; Chow \& Cummings, 2000; Tisserand, Visser, van Boxtel, \& Jolles, 2000) and functionally (Gutchess, Kensinger, \& Schacter, 2007; Williams et al., 2006). On the other hand, however, are studies that have suggested that the valence of information (whether positive or negative) may fundamentally influence the way in which older adults process and remember emotional information. A number of studies have revealed a "positivity shift" with aging; whereas young adults are more likely to remember negative information than positive or neutral information, older adults may be at least as likely (or even more likely) to remember positive information compared with negative information (Mather \& Carstensen, 2005).

It has been proposed that this "positivity shift" may occur because older adults put more emphasis on emotion regulation goals than do young adults, with older adults having a greater motivation to derive emotional meaning from life and to maintain positive affect (e.g., Mather \& Carstensen, 2005). In the service of these goals, older adults may focus their attention on things that will elicit pleasant feelings (Mather, 2006; Carstensen, Isaacowitz, \& Charles, 1999) and may process positive information in a more self-referential fashion (Gutchess et al., 2007). Although this argument has some empirical 
support, behavioral data do not always support the conclusion that older adults' "positivity shift" results from changes in encoding processes. For example, when performing a digit parity task in which positive or negative distractor words were presented in between the two numbers that were to be evaluated, older adults did not show a disproportionate interference effect from the positive words compared to the negative words. Nevertheless, the older adults did later remember the positive words better than the negative words (Thomas \& Hasher, 2006). These findings suggest that older adults' positivity bias may not arise from increased attention toward positive items at the time of encoding. However, when older adults' attentional resources are taxed during encoding (by use of a divided attention manipulation), their positivity effect disappears (Mather \& Knight, 2005), suggesting that there may be a link between the way in which older adults process positive versus negative at encoding that leads to their mnemonic benefit for positive information.

The present functional magnetic resonance imaging study used a subsequent-memory paradigm, in which encoding-related activity to items of different valences was analyzed as a function of whether the items were later remembered or forgotten (for more information on the use of the subsequent-memory paradigm, see review by Paller \& Wagner, 2002). Thus, the present study could examine whether there are age-related changes in the neural processes supporting the successful encoding of emotional information, and whether such changes could explain older adults' positivity shift. If age-related changes in encoding processes correspond with the positivity shift, then it should be possible to demonstrate age-related changes in the neural processes that predict subsequent memory for positive information. We therefore compared the neural processes that young and older adults recruited as they encoded positive, negative, and neutral information. This design allowed us to examine subsequent-memory effects that generalize to all emotional items (i.e., positive and negative ones) and also to uncover subsequent-memory effects that are valence-specific (i.e., that correspond with memory for positive but not negative items, or vice-versa).

To accomplish these goals, we used a paradigm previously shown to lead to an emotional memory enhancement only for negative information in young adults but to lead to a broader emotional memory enhancement for negative and positive information in older adults (Kensinger, Garoff-Eaton, \& Schacter, 2007a, 2007b). In this paradigm, young and older adults are shown objects, some with negative content (e.g., a snake), some with positive content (e.g., a sundae), and others with neutral content (e.g., a canoe). After a delay, participants are shown another series of objects and are asked to discriminate items that are the "same" (identical to studied objects) from objects that are "similar" (share the same verbal label as a studied object, but differ in visual details) or from objects that are "new" (unrelated to a studied object). The "positivity shift" is manifest in the fact that young adults perform well when judging whether negative objects are "new," but perform equally poorly when judging whether neutral or positive objects are "new." By contrast, older adults are equally good at knowing whether negative or positive objects are "new."

An important feature of this paradigm is that it can distinguish memory for an object's visual details (i.e., a participants" ability to know that something is "same" rather than "similar") from memory for an object's gist or general theme (i.e., a participants' ability to know that something is not "new"). This distinction is an important one to make because previous behavioral research has demonstrated that negative items are more likely to be remembered with visual detail than neutral or positive items (Kensinger, 2007). Importantly, this valencespecific boost for visual details occurs for both young and older adults. Older adults, just like young adults, remember the visual details of negative objects more frequently than they remember the visual details of positive or neutral objects, and they show no boost in memory for the visual details of positive items as compared to neutral ones (e.g., Kensinger, Garoff-Eaton, \& Schacter, 2007c; Kensinger, O’Brien, Swanberg, Garoff-Eaton, \& Schacter, 2007; Kensinger et al., 2007a, 2007b). This preservation sets up an interesting contrast regarding older adults' emotional memories: Although older adults show a benefit for remembering the general theme of positive information, they show no benefit for remembering the specific visual details of positive items and, in fact, are better at remembering negative items' visual details.

These findings suggest that there is something different about the way in which positive and negative information is processed, such that across the adult lifespan, negative information is remembered with more detail than positive information. Positive information may be processed in a gist-like or heuristic fashion, with attention drawn to the general features of the presented information but not the exact details. By contrast, negative information may be processed in a more detail-oriented and analytic fashion, with attention focused on the item details (e.g., Gasper \& Clore, 2002; Bless et al., 1996). Although behavioral evidence supports such a distinction (e.g., Kensinger \& Schacter, 2006; Storbeck \& Clore, 2005; Levine \& Bluck, 2004; Ochsner, 2000), it is not known how the neural circuitry recruited during the processing of positive and negative information leads to these different effects on memory. Nor is it understood why aging changes the proportion of positive information remembered (i.e., results in a "positivity shift") but not the visual details remembered about positive items. The present study explored these open questions regarding the emotional memory network. 


\section{METHODS}

\section{Participants}

Seventeen young adults ( 5 men and 12 women; ages 19-31 years; mean age $=21.6$ years) and 20 older adults ( 7 men and 13 women; ages $62-79$ years; mean age $=$ 73.3 years) participated in this study. The data from three older adults ( 1 man and 2 women) were excluded due to difficulty following task instructions (one participant) or chance performance on the subsequent memory task (two participants). All participants were native English speakers who had normal or corrected-to-normal vision, and all were screened to exclude those with any contraindicators for magnetic resonance imaging scanning or with any history of neurological trauma or psychiatric disorder (e.g., depression or anxiety disorder). No participant reported that they were currently taking any medications that affected the central nervous system. Informed consent was obtained from all participants in a method approved by the Harvard University, Boston College, and Massachusetts General Hospital Institutional Review Boards.

Older adults had an average of 17.5 years of education, consistent with the level of education completed (or expected to be completed) by the young adults (young adults had an average of 15.2 years of education, and all were either enrolled in a bachelor's program or had already received their bachelor's degree). Older adults performed as well as young adults on the forward and backward digit span, significantly better than young adults on the WAIS-III (Wechsler, 1997) vocabulary subtest, and significantly worse than young adults on the WAIS-III digit/symbol copy subtest (see Table 1 for test scores). This pattern of performance is consistent with that typically associated with healthy aging (Kensinger \& Corkin, 2003), and there were no differences in the age-adjusted scores on the WAIS-III subtests, suggesting that the two age groups were generally well-matched. All older adults achieved scores of 28 or higher on the Mini-Mental Status Examination (Folstein, Folstein, \& McHugh, 1975).

\section{Materials and Procedure}

Materials comprised 435 pairs of colored, nameable photo objects (Hemera Technologies, 2002, Canada), sized to 300 pixels in their largest dimension. Pairs of objects were selected so that the two items of a pair shared the same verbal label (e.g., were both umbrellas) but differed in other perceptual features (e.g., color, shape, size, orientation). Object pairs were selected from those used by Kensinger et al. (2007a, 2007b) and Kensinger, GaroffEaton, and Schacter (2006); as described in those papers, young and older adults rated objects on 9-point Likert scales for valence (with low numbers signifying negative objects and high numbers signifying positive objects) and arousal (with high numbers indicating high arousal). We selected 145 object pairs that had been judged by young and older adults to be negative and arousing (valence ratings of less than 3.5 and arousal ratings of greater than 5), 145 object pairs that had been rated as positive and arousing (valence ratings greater than 5.5 and arousal ratings greater than 5 ), and 145 object pairs that had been determined to be neutral and nonarousing (valence ranging between 3 and 6 and arousal less than 5). Pairs also were selected to assure that the negative and positive objects had similar arousal levels and similar absolute valence levels (i.e., distances from neutral valence) to one another (all $p>$.15), and so that the positive and negative items differed significantly from the neutral items in both valence and arousal $(p<.001)$. Pairs also were selected so that there were no age differences in the ratings of objects based upon their valence and arousal (all $p>.15$ ). Furthermore, positive, negative, and neutral item pairs were matched to one another with regard to the overall similarity of the two items, the dimensions (color, size, shape, orientation) that differed between the two items, and the familiarity of the items (as determined by familiarity values for the verbal referents of the objects).

\section{Study Procedure}

While in the functional magnetic resonance imaging scanner, participants were presented with 324 nameable,

Table 1. Mean $(S E)$ Test Scores for Participants

\begin{tabular}{|c|c|c|c|c|c|c|c|}
\hline \multirow[b]{3}{*}{ Age Group } & \multirow[b]{3}{*}{$M M S E$} & \multirow{2}{*}{\multicolumn{2}{|c|}{ Digit Span }} & \multicolumn{2}{|c|}{ WAIS-III Digit/Symbol } & \multicolumn{2}{|c|}{ WAIS-III Vocabulary } \\
\hline & & & & Number & Age-adjusted & Percentage & Age-adjusted \\
\hline & & Forward & Backward & Completed $^{a}$ & Scaled Score & Correct $^{a}$ & Scaled Score \\
\hline Young adults & $\mathrm{N} / \mathrm{A}$ & $6.94(0.43)$ & $5.12(0.27)$ & $71.3(3.2)$ & $9.8(0.53)$ & $81.7(2.2)$ & $16.1(0.33)$ \\
\hline Older adults & $29.6(0.08)$ & $6.18(0.27)$ & $4.82(0.36)$ & $48.8(2.3)$ & $10.1(0.46)$ & 88.9 (1.9) & $16.5(0.47)$ \\
\hline
\end{tabular}

MMSE $=$ Mini-Mental Status Examination (Folstein et al., 1975); WAIS-III = Wechsler Adult Intelligence Scale, 3rd Edition (Wechsler, 1997).

Older adults completed significantly fewer entries on the digit/symbol copy than young adults, and older adults correctly defined more words on the Vocabulary assessment than young adults; however, the age groups did not differ from one another in their age-adjusted scaled scores on either of these tasks.

${ }^{a}$ Measure on which there was a significant age difference $(p<.05)$. 
colored objects. These objects were presented across three lists, with each list containing 108 items (36 negative, 36 positive, 36 neutral). Each item was presented for 1 sec. Participants made a size decision about whether each object, in the real world, would fit inside of a filing cabinet drawer. Participants were asked to make this decision as quickly as possible. Emotion of the item did not affect participants' reaction times to make the decisions about the objects. Following the item's presentation, a fixation cross $(+)$ was presented for a variable duration (range of 5-13 sec) to provide jitter (Dale, 1999).

\section{Test Procedure}

Outside of the scanner, after approximately a 30-min delay, participants performed a surprise object recognition task. On the recognition task, participants were presented with 432 objects: 216 objects (72 negative, 72 positive, 72 neutral) were identical to those that had been studied (same objects); 108 objects (36 negative, 36 positive, 36 neutral) shared the same verbal label as a studied item but differed in color, size, shape, or orientation (similar objects); and 108 were new objects (36 negative, 36 positive, 36 neutral; Figure 1). Each object appeared in the center of a computer screen, with a prompt below indicating that participants should indicate, by keypress, whether the item was same, similar, or new. The member of the object pair that was included on the recognition task was held constant for all participants; the particular items presented at study were counterbalanced between participants to manipulate the condition of each object shown at recognition.

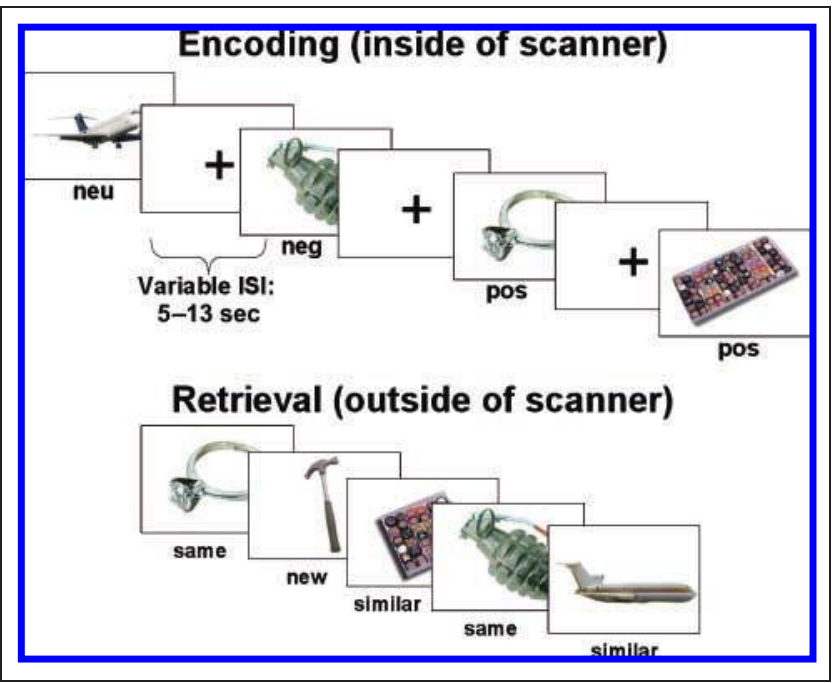

Figure 1. Task design. At encoding, participants viewed a series of photo objects and judged whether each would fit inside a file cabinet drawer. During retrieval, participants determined whether each object was the "same" (identical) as a studied object, was "similar" (shared the same verbal label, but differed in visual detail), or was "new" (different verbal label than any studied item).
The neuroimaging analyses focus on participants' encoding of items later tested with the same exemplar. ${ }^{1}$ If a participant gave a "same" response to a same item, this signifies memory for the visual details of that item ("specific recognition"); a "similar" response indicates memory for the general type of item but not for its exact visual details ("nonspecific recognition"); and a "new" response reflects complete forgetting of the item's presentation. Taken together, a "same" or a "similar" response to a same item indicates memory for at least the general features of an item (referred to throughout as "general recognition").

\section{Image Acquisition and Data Analysis}

Images were acquired on a 3-Tesla Siemens Allegra MRI scanner. Detailed anatomic data were acquired using a multiplanar rapidly acquired gradient-echo (MP-RAGE) sequence. Functional images were acquired using a T2*weighted echo-planar imaging (EPI) sequence $(\mathrm{TR}=$ $3000 \mathrm{msec}, \mathrm{TE}=30 \mathrm{msec}, \mathrm{FOV}=200 \mathrm{~mm}$; flip angle $=$ $90^{\circ}$ ). Twenty-eight axial-oblique slices $(3.2 \mathrm{~mm}$ thickness, $0.6 \mathrm{~mm}$ skip between slices), aligned along the anterior commissure/posterior commissure line, were acquired in an interleaved fashion.

All preprocessing and data analysis were conducted within SPM2 (Wellcome Department of Cognitive Neurology). Standard preprocessing was performed on the functional data, including slice-timing correction, rigidbody motion correction, normalization to the Montreal Neurological Institute template (resampling at $3 \mathrm{~mm}^{3}$ voxels), and spatial smoothing (using a 7.6-mm fullwidth half-maximum isotropic Gaussian kernel).

For each participant, and on a voxel-by-voxel basis, an event-related analysis was first conducted in which all instances of a particular event type were modeled through convolution with a canonical hemodynamic response function. Analyses focused on subsequent memory for items tested as the same exemplar on the recognition task, and all participants had at least 15 instances of "same," "similar," and "new" responses to the same items from each emotion category. Effects for each event type were estimated using a subject-specific fixed-effects model. These data were then entered into a second-order random-effects analysis.

Random-effects analyses contrasted activation as a function of subsequent memory performance separately for each emotion type (negative, positive, or neutral), and interaction analyses revealed the regions that related more strongly to subsequent memory performance for one emotion type than for another. Conjunction analyses (using the masking function in SPM) were used to examine the regions that showed activation in a particular contrast (or interaction analysis) in both young and older adults, and group comparisons were conducted to reveal what regions showed a greater correspondence to subsequent memory performance in one 
age group than in the other. Contrasts entered into the conjunction analyses were analyzed with a $p<.01$ and 5-voxel extent threshold. Thus, the conjoint probability of the conjunction analysis was $p<.001$, uncorrected (Lazar, Luna, Sweeney, \& Eddy, 2002; Fisher, 1950). Group comparison analyses were conducted with a $p<.001$ and 5-voxel extent threshold. All activations are presented in neurological coordinates (i.e., activity on the right hemisphere is presented on the right side of the brain images). Voxel coordinates are reported in Talairach and Tournoux (1988) coordinates and identify the peak voxel within the cluster of activation.

Event-related time courses were extracted from active clusters by creating regions of interest (ROIs), including all significant voxels within a $5-\mathrm{mm}$ radius of each chosen maximum voxel, using the ROI toolbox implemented in MarsBar (Brett, Anton, Valabregue, \& Poline, 2002). Within each of these ROIs, a hemodynamic response function was calculated for each individual subject and for each condition type (relative to fixation baseline) as a function of peristimulus time (0-21 sec). Statistics were performed on the sum of the signal change within a peristimulus time of 3-12 sec. These signal change values are displayed in the figures. Analysis of variance (ANOVA) was performed on these extracted signal change values to examine whether the ROIs showed an interaction between memory accuracy and emotion type (e.g., activity relating to memory for the visual details of an negative item but not for visual details of a neutral or positive item), between memory accuracy and age (e.g., activity relating more strongly to memory for visual details for young adults than for older adults, or vice versa), or a three-way interaction among memory accuracy, detail type, and age.

\section{RESULTS}

Behavioral and neuroimaging data were analyzed with participants' sex as a factor. No main effects of sex or interactions between age and sex were revealed. Therefore, all reported analyses collapse together data from men and women. As in previous studies using variants of this paradigm (Kensinger, Garoff-Eaton, et al., 2007c; Kensinger, O'Brien, et al., 2007; Kensinger et al., 2006; Garoff, Slotnick, \& Schacter, 2005), we focus on subsequent memory effects for items later tested as a same exemplar (but see Table 2 for distribution of responses to all tested items). We considered "same" responses to same studied items to reflect memory for specific visual details ("specific recognition") and "similar" responses to same studied items to indicate memory for some (but not all) aspects of the studied item ("nonspecific recognition"). Collectively, we considered "same" or "similar" responses to same studied items to indicate memory for at least the general theme of the studied item ("general recognition").

\section{Behavioral Results}

An ANOVA conducted on the general recognition scores revealed an interaction between age and valence $(p<$ .01): Whereas young adults showed better general recognition for negative items than for positive or neutral ones (i.e., negative $>$ positive $=$ neutral), older adults showed equally good general recognition for negative and positive items (i.e., negative $=$ positive $>$ neutral; see Table 2). This pattern of results is consistent with the "positivity shift" that has been reported in a number of prior studies (Mather \& Carstensen, 2005). Although the strongest instantiation of the "positivity shift" occurs when older adults remember more positive information than negative or neutral information, the more common pattern of results is exactly what we see in the present study: Older adults show a mnemonic benefit for positive information, whereas young adults do not (e.g., Charles, Mather, \& Carstensen, 2003, Experiment 2; Kensinger, Garoff-Eaton, et al., 2007c; Kensinger, O'Brien, et al., 2007; Kensinger et al., 2007a, 2007b). This "positivity shift" was also evidenced by the fact that, as compared to young adults, older adults showed poorer general recognition for the neutral and negative items, whereas the two age groups had similar general recognition scores for the positive items (see Table 2).

To examine whether these age-related changes arose due to changes in "specific recognition" or in "nonspecific recognition," we conducted separate ANOVAs on each of these recognition scores. An ANOVA conducted on the specific recognition scores revealed a main effect of age (older adults had poorer specific recognition overall than young adults; $p<.01$ ) and a main effect of valence (specific recognition was higher for negative items than for positive or neutral items; $p<.01$ ), but no interaction between age and valence $(F<1)$. Both young and older adults showed enhanced specific recognition for negative items as compared to positive or neutral ones (see Table 2). Thus, negative, but not positive, content enhanced the visual specificity of memory in both age groups. By contrast, an ANOVA conducted on the nonspecific recognition scores revealed a significant interaction between age and valence $(p<.01)$; thus, the older adults' "positivity shift" appears to stem not from effects of positive emotion on memory for visual specifics, but rather from effects on memory for the general theme of previously presented objects.

\section{Neuroimaging Results}

All neuroimaging analyses report subsequent-memory effects (Paller \& Wagner, 2002). Analyses focus primarily on subsequent "general recognition" memory, which most closely parallels standard assessments of recognition memory (i.e., most recognition memory decisions can be supported either by memory for specific details or by memory for the general theme of the studied 
Table 2. Proportion of "Same," "Similar," and "New" Responses [Mean (SE)] as a Function of Item Type (Same, Similar, or New), Emotion Type (Positive, Negative, Neutral), and Age (Young, Older Adults)

\begin{tabular}{llll}
\hline & Same Exemplar & Similar Exemplar & New Exemplar \\
\hline Young Adults & & & \\
Positive Objects & & & \\
"Same" response & $0.52(0.02)$ & $0.22(0.04)$ & $0.09(0.01)$ \\
"Similar" response & $0.24(0.03)$ & $0.43(0.03)$ & $0.24(0.03)$ \\
"New" response & $0.24(0.02)$ & $0.35(0.03)$ & $0.66(0.04)$ \\
Negative Objects & & $0.23(0.03)$ & $0.09(0.02)$ \\
"Same" response & $0.57(0.02)$ & $0.42(0.04)$ & $0.26(0.03)$ \\
"Similar" response & $0.23(0.03)$ & $0.35(0.03)$ & $0.64(0.03)$ \\
"New" response & $0.20(0.02)$ & & $0.09(0.01)$ \\
Neutral Objects & & $0.21(0.03)$ & $0.24(0.03)$ \\
"Same" response & $0.50(0.02)$ & $0.41(0.02)$ & $0.66(0.03)$
\end{tabular}

Older Adults

Positive Objects

$\begin{array}{llll}\text { "Same" response } & 0.45(0.02) & 0.21(0.04) & 0.06(0.01) \\ \text { "Similar" response } & 0.29(0.03) & 0.34(0.05) & 0.17(0.03) \\ \text { "New" response } & 0.25(0.02) & 0.45(0.04) & 0.77(0.04) \\ \text { Negative Objects } & & & 0.21(0.03) \\ \text { "Same" response } & 0.50(0.02) & 0.33(0.03) & 0.20(0.02) \\ \text { "Similar" response } & 0.26(0.03) & 0.47(0.04) & 0.74(0.03) \\ \text { "New" response } & 0.25(0.02) & 0.27(0.05) & 0.05(0.01) \\ \text { "Same" response } & & 0.30(0.03) & 0.17(0.02) \\ \text { "Similar" response } & 0.44(0.02) & 0.43(0.02) & 0.78(0.03) \\ \text { "New" response } & 0.26(0.03) & 0.31(0.02) & \end{array}$

Specific recognition reflects the proportion of "same" responses to same items, nonspecific recognition reflects the proportion of "similar" responses to same items, and general recognition reflects the sum of "same" or "similar" responses to same items.

item). Thus, responses to studied items later tested as a same exemplar were sorted based upon whether participants later remembered at least the general theme of the item ("same" or "similar" response to the same item) or later forgot the item ("new" response to the same item). We did extract signal change values separately for items associated with "specific recognition" and for items associated with "nonspecific recognition" to be able to examine whether regions corresponded more strongly with one type of memory than the other; figures depicting signal change values are therefore broken down by specific versus nonspecific recognition.
Regions Related to Subsequent General Recognition, Regardless of Emotional Content

We first examined the effect of age on the neural processes predictive of subsequent general recognition memory for all items, regardless of their emotional content. We used conjunction analyses to reveal regions that were related to subsequent-memory performance for both young and older adults, and group comparison analyses to reveal regions that were disproportionately related to subsequent-memory performance for one age group compared to the other. These analyses revealed 
Table 3. Regions that Corresponded with Subsequent General Recognition for All Items (Positive, Negative, or Neutral)

\begin{tabular}{|c|c|c|c|c|}
\hline Lobe & Region & Hemisphere & Brodmann's Area & Talairach Coordinates \\
\hline \multicolumn{5}{|c|}{ Young and Older Adults } \\
\hline Frontal & Middle frontal gyrus & $\mathrm{R}$ & $9 / 10$ & $30,54,10$ \\
\hline Temporal & Parahippocampal gyrus & $\mathrm{L}$ & 36 & $-38,-32,-14$ \\
\hline \multirow[t]{3}{*}{ Occipital } & Fusiform gyrus & $\mathrm{L}$ & $18 / 19$ & $-34,-80,-2$ \\
\hline & Cuneus & $\mathrm{L}$ & 30 & $-20,-91,10$ \\
\hline & & $\mathrm{R}$ & & $14,-67,13$ \\
\hline \multicolumn{5}{|c|}{ Young but not Older Adults } \\
\hline Temporal & Hippocampus/parahippocampal gyrus & Bilateral & - & $-28,-18,-13$ \\
\hline & & & & $26,-14,-12$ \\
\hline \multicolumn{5}{|c|}{ Older but not Young Adults } \\
\hline \multirow[t]{6}{*}{ Frontal } & Medial frontal gyrus & $\mathrm{L}$ & 10 & $-16,64,4$ \\
\hline & & $\mathrm{L}$ & 9 & $-6,52,20$ \\
\hline & & $\mathrm{L}$ & 10 & $-2,65,17$ \\
\hline & & $\mathrm{R}$ & 10 & $8,56,3$ \\
\hline & Middle frontal gyrus & $\mathrm{L}$ & 10 & $-38,54,1$ \\
\hline & Inferior frontal gyrus & $\mathrm{R}$ & 45 & $52,25,1$ \\
\hline Temporal & Middle temporal gyrus & $\mathrm{R}$ & 22 & $58,-33,5$ \\
\hline \multirow[t]{2}{*}{ Other } & Insula & $\mathrm{R}$ & 13 & $44,-17,4$ \\
\hline & Anterior cingulate gyrus & Bilateral & 32 & $0,43,-7$ \\
\hline
\end{tabular}

All regions consist of at least 5 voxels.

that, for both young and older adults, a network of regions in the temporal, parietal, and occipital cortices corresponded with successful encoding (i.e., activity was greater during the encoding of items given a "same" or "similar" response as compared to a "new" response; see upper panel of Table 3). However, there also were important age differences in the neural processes engaged. In particular, young adults showed more medial temporal lobe engagement than older adults (see middle panel of Table 3) and older adults showed more prefrontal engagement than young adults (see lower panel of Table 3). These results are consistent with other evidence suggesting that, with aging, individuals may recruit fewer medial temporal lobe mnemonic processes and more prefrontal mnemonic processes (e.g., Gutchess et al., 2005).

\section{Memory for Negative and Positive Compared to Neutral Information}

Although these results replicated the major findings from prior studies examining the effects of aging on episodic encoding, the primary goal of the present study was to examine the neural processes that relate to young and older adults' memories for positive and negative information. We used conjunction analyses to reveal the neural processes that corresponded with subsequent general recognition memory for positive information and also with negative information, but not with neutral information. Conjunction analyses revealed that activity in the amygdala (Talairach coordinates: $15,-5,-18$ ) and in the orbito-frontal cortex (BA 11/47, Talairach coordinates: $30,14,-14)$, as well as in the lateral parietal lobe (BA 40, Talairach coordinates: 46, -38, 36), showed this correspondence for both young and older adults (Figure 2). No regions showed this correspondence disproportionately for one age group as compared to the other.

\section{Regions Related to Subsequent General Recognition of Negative but not Positive or Neutral Information}

To examine the neural processes that were related more strongly to the successful encoding of negative information as compared to positive or neutral information, we conducted interaction analyses to reveal the regions that were disproportionately related to subsequent general 


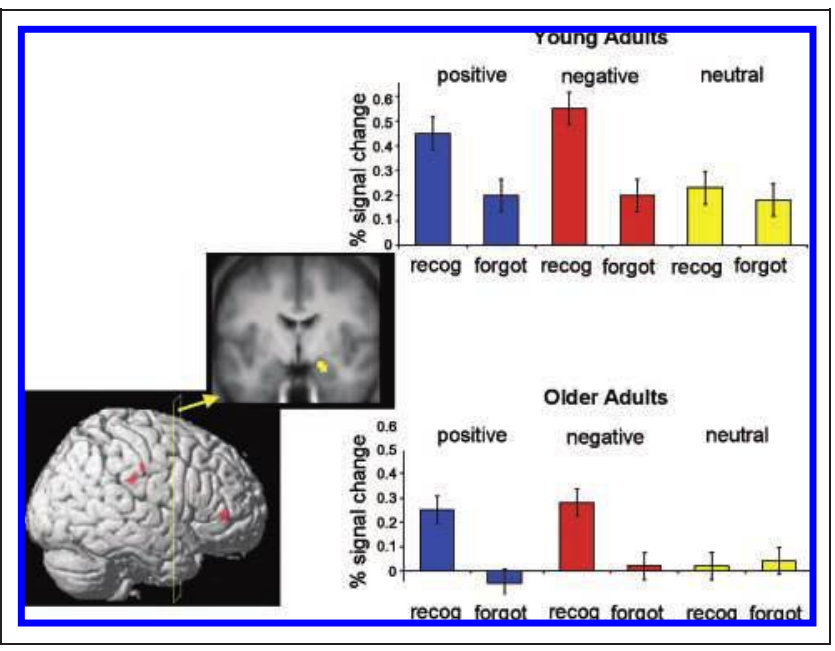

Figure 2. Regions recruited by both young and older adults during the successful encoding of positive and negative (but not neutral) items. These regions included the amygdala (shown on the coronal slice, $y=-6$ ) as well as regions of the orbito-frontal cortex and lateral parietal cortex. Graphs depict signal change in the amygdala, demonstrating that young and older adults both showed a correspondence between amygdala activity and subsequent memory for positive and negative items, but no correspondence between amygdala activity and later memory for neutral items.

recognition of negative items compared with the subsequent general recognition of positive or neutral items (i.e., ["same" or "similar" to negative item > "new" response to negative item] > ["same" or "similar" to positive or neutral item $>$ "new" response to positive or neutral item]). A conjunction analysis was conducted to examine the regions that showed this correspondence for both young and older adults, and group comparison analyses were conducted to examine the regions that showed this correspondence more strongly for one age group than for the other.

The conjunction analysis revealed that, for both young and older adults, activity in the right fusiform gyrus (Talairach coordinates: 20, $-64,-3$, BA 19/37; Figure 3) showed a greater correspondence to memory for negative items than for positive or neutral items. Importantly, the group comparison analyses revealed no regions that were disproportionately recruited by young adults or by older adults for the successful encoding of negative items. Thus, the main distinction between regions predictive of later memory for negative compared to positive and neutral items appears to be visual engagement, and this distinction is constant across age groups. Indeed, when signal change was analyzed as a function of the type of recognition response given to a same item, the pattern of activity in the right fusiform gyrus was found to be much greater for items later given a "same" response (i.e., for items later remembered with visual detail) than for items later given a "similar" response (see lower panels of Figure 3). This link between right fusiform activity and the encoding of specific visual detail was equally strong for the young and older adults; there was no Memory $\times$ Age interaction, nor a three-way Memory $\times$ Age $\times$ Emotion interaction.

\section{Regions Related to Subsequent General Recognition of Positive but not Negative or Neutral Information}

To examine the neural processes related to successful encoding of positive as compared to negative or neutral
Figure 3. Regions that showed a stronger correspondence to subsequent general recognition for the negative items than for the neutral or positive items. Only a region of the right fusiform gyrus showed a stronger correspondence to general recognition (i.e., a greater discrepancy between activity during the encoding of items that would later be recognized [recog] vs. forgotten [forgot]) for the negative items (red bars) than for the positive (blue bars) or neutral items (yellow bars). This pattern was evident for both the young adults (left panel) and older adults (right panel). When signal change for the recognized items was

broken down by response type to the same items (lower panels), the results revealed that the region's activity was greatest for items later recognized with specific visual detail (i.e., was greater for items correctly given a "same" response than for items incorrectly given a "similar" response). 
information, analyses were conducted that mirrored those described in the previous Results section. We conducted interaction analyses to reveal the regions that were disproportionately engaged during the successful encoding of positive items compared to during the successful encoding of negative or neutral items (i.e., ["same" or "similar" to positive item > "new" response to positive item] > ["same" or "similar" to negative or neutral item $>$ "new" response to negative or neutral item]). We then conducted a conjunction analysis to examine the regions that showed this correspondence for both young and older adults, and we performed group comparison analyses to examine the regions that showed this correspondence more strongly for one age group than for the other.

The conjunction analysis revealed a large frontotemporal network of regions that were more strongly associated with memory for positive items than with memory for negative or neutral items in both young and older adults (see Table 4). These regions within the left prefrontal cortex and the left temporal lobe are consistent with those often involved in conceptual processing (e.g., Dobbins \& Wagner, 2005; Poldrack et al., 1999), and their engagement may reflect the schematic or heuristic processing of positive items. Consistent with this interpretation, these regions' activity was equally strong for all items that were later recognized, regardless of whether the items were later remembered with visual detail (i.e., were later given a correct "same" response) or with only nonspecific information (i.e., were given an incorrect "similar" response; see Figure 4). This pattern of results suggests that these regions' engagement corresponded with encoding of information about the general theme of an item (e.g., its verbal label or semantic attributes) but not its visually specific details.

Group comparison analyses revealed that there were no regions disproportionately employed by the young compared to the older adults, consistent with the behavioral finding that young adults did not show a mnemonic enhancement for positive items as compared to neutral ones. In contrast, older adults showed a stronger correspondence between medial prefrontal and cingulate gyrus activity and memory for positive items than did young adults (see Figure 4).

\section{DISCUSSION}

The results of the present study reveal age-related preservation in the neural processes that are recruited during the successful encoding of emotional items. Both young and older adults recruited the amygdala and the orbito-frontal cortex during the encoding of emotional items but not during the encoding of neutral items. These limbic regions frequently have been implicated in

Table 4. Regions that were Related to Subsequent General Recognition of Positive Items, but not of Negative or Neutral Ones

\begin{tabular}{|c|c|c|c|c|}
\hline Lobe & Region & Hemisphere & Brodmann's Area & Talairach Coordinates \\
\hline \multicolumn{5}{|c|}{ Young and Older Adults } \\
\hline \multirow[t]{3}{*}{ Frontal } & Superior frontal gyrus & $\mathrm{R}$ & 10 & $20,66,7$ \\
\hline & Middle frontal gyrus & $\mathrm{L}$ & 10 & $-28,59,21$ \\
\hline & Inferior frontal gyrus & $\mathrm{L}$ & $45 / 47$ & $-52,30,8$ \\
\hline Parietal & Precuneus/posterior cingulate gyrus & $\mathrm{R}$ & 31 & $16,-47,32$ \\
\hline \multirow[t]{2}{*}{ Temporal } & Middle temporal gyrus & $\mathrm{L}$ & 21 & $-63,-54,6$ \\
\hline & Superior temporal gyrus & $\mathrm{L}$ & 22 & $-57,-36,11$ \\
\hline Limbic & Parahippocampal gyrus & $\mathrm{L}$ & $28 / 35$ & $-21,-18,-11$ \\
\hline Subcortical & Caudate & $\mathrm{R}$ & - & $14,-32,25$ \\
\hline \multicolumn{5}{|c|}{ Young but not Older Adults } \\
\hline \multicolumn{5}{|c|}{ No regions revealed } \\
\hline \multicolumn{5}{|c|}{ Older but not Young Adults } \\
\hline Frontal & Medial frontal gyrus & Bilateral & 10 & $0,33-10$ \\
\hline \multirow[t]{3}{*}{ Limbic } & Anterior cingulate gyrus & $\mathrm{L}$ & 24 & $-8,26,10$ \\
\hline & & $\mathrm{R}$ & 33 & $10,11,25$ \\
\hline & Posterior cingulate gyrus & $\mathrm{L}$ & 23 & $-8,-45,26$ \\
\hline
\end{tabular}

All regions consist of at least 5 voxels. 
Figure 4. Regions that showed a stronger correspondence to subsequent general recognition (i.e., subsequently recognized $>$ subsequently forgotten) for the positive items than for the neutral or negative items. Red regions showed this correspondence for both young and older adults. Green regions showed this correspondence for the older adults but not for the young adults. No regions showed this correspondence for the young adults but not the older adults, consistent with the behavioral finding that only older adults showed mnemonic enhancement for the positive items. Graphs depict percentage signal change from the region of the left prefrontal cortex circled in yellow, representative of the types of activity patterns noted throughout the prefrontal and temporal lobe regions revealed by this analysis. This region showed a stronger correspondence to general recognition (i.e., a greater discrepancy between activity during the encoding of items that would later be recognized [recog] vs. forgotten [forgot]) for the positive items (blue bars) than for the negative (red bars) or neutral items (yellow bars). This pattern was evident for both the young adults (left panel) and older adults (right panel). When signal change for the recognized items was broken down by response type to the same items (lower panels), the results revealed that the region's activity was equivalent regardless of whether items were later recognized with specific visual detail (i.e., were correctly given a "same" response) or with only nonspecific information (i.e., were incorrectly given a "similar" response).

young adults' successful encoding of emotional information (LaBar \& Cabeza, 2006), and the present results suggest that these regions retain their role in emotional memory across the adult lifespan.

These results are interesting in light of debates regarding the stability of the emotional processing network with aging. Although some studies have suggested age-related preservation of amygdala recruitment during emotional processing (Wright, Wedig, Williams, Rauch, \& Albert, 2006), other studies have suggested that aging may be associated with reductions in amygdala recruitment - at least during the processing of negative stimuli (e.g., fearful and angry facial expressions or negative colored photographs; Tessitore et al., 2005; Mather et al., 2004; Gunning-Dixon et al., 2003). Older adults also sometimes show overrecruitment of prefrontal regions during the processing of negatively emotional information, leading some to hypothesize that older adults may engage in active regulation of their negative emotion states (e.g., Williams et al., 2006; Tessitore et al., 2005). The present study cannot settle this debate. However, the current findings suggest that, if there are age-related changes in amygdala recruitment during emotional processing, these changes are not sufficient to eliminate the amygdala's role in emotional memory. There may be age-related changes in emotion regulation or in the prioritization of emotion-related goals (e.g.,
Carstensen et al., 1999; Gross et al., 1997; Labouvie-Vief, 1982), but these changes do not appear to fundamentally alter the core of the emotional memory network.

Young and older adults also showed similarities in the valence-specific processes that supported the successful encoding of negative versus positive information. In particular, both age groups recruited the right fusiform gyrus disproportionately during the encoding of negative items but showed additional recruitment of prefrontal and lateral temporal regions during the encoding of positive items. These valence-specific processes dovetail nicely with the behavioral evidence that young and older adults remember visual details more for negative than for positive items, and remember positive information in a more schematic or general fashion (Kensinger et al., 2007a, 2007b; Storbeck \& Clore, 2005; Gasper \& Clore, 2002; Bless et al., 1996). The right fusiform gyrus often has been implicated in the processing of specific visual details. Activation of this region during encoding corresponds with memory for visual details (Kensinger, Garoff-Eaton, et al., 2007c; Garoff et al., 2005), and priming-related decrements in this region occur only when the visual details of an object remain stable across item repetitions (Koutstaal et al., 2001). Thus, it makes sense that additional recruitment of this region during the encoding of negative items would correspond with better memory for those negative items' visual features. 
Indeed, in the present study, the right fusiform activity was greater during the encoding of items that later would be remembered with visual detail (i.e., for same items correctly given a "same" response) than for items later remembered without visual detail (i.e., for same items incorrectly given a "similar" response). By contrast, the prefrontal and temporal regions that showed a disproportionate correspondence to memory for the positive items are regions associated with conceptual processing. For example, the left prefrontal cortex, and particularly the left anterior prefrontal region revealed here (BA 45/47), has been implicated in the retrieval of conceptual details (Dobbins \& Wagner, 2005) and in conceptual and semantic priming (e.g., Poldrack et al., 1999). Thus, it makes sense that recruitment of these regions may relate to the processing of general, conceptual information about positive objects. The present results support this conclusion, with encoding-related activity in these regions being equally high for all items recognized with at least general information (i.e., with equivalent levels of activity for items later given a correct "same" response or an incorrect "similar" response).

These results, therefore, suggest that at least part of the distinct effects of valence arise due to the influences of encoding processes. It may be that participants' attention is directed toward different features of negative versus positive items (e.g., to perceptual rather than conceptual attributes) and that these differences influence the types of information later remembered about the items. The results further emphasize that the influence of valence upon encoding processes remains consistent across the adult lifespan. Despite evidence that older adults focus more on positive information than young adults (Mather \& Carstensen, 2005), aging does not appear to disrupt the types of valence-specific processes recruited during information processing.

Although there were these extensive commonalities among the processes engaged during young and older adults' successful encoding of emotional information, there also was age-associated divergence during the encoding of the positive items. In particular, older adults recruited the medial prefrontal cortex and the cingulate gyrus more than young adults during the successful encoding of positive information. The fact that older adults showed this additional correspondence between encoding-related activity and subsequent memory suggests that the "positivity shift" occurs, at least in part, due to age-related differences in how information is processed upon initial encounter.

The fact that it was these particular regions that showed the age-related divergence is particularly intriguing given these regions' purported roles in self-referential processing $^{2}$ (D'Argembeau et al., 2005; Macrae, Moran, Heatherton, Banfield, \& Kelley, 2004; Kelley et al., 2002; Craik et al., 1999; see meta-analysis by Northoff et al., 2006), a type of processing that enhances the effectiveness of encoding (Rogers, Kuiper, \& Kirker, 1977; see Symons
\& Johnson, 1997 for a review). This self-referential mnemonic boost extends to older adults (Gutchess, Kensinger, Yoon, \& Schacter, 2007; Mueller, Wonderlich, \& Dugan, 1986), and so it makes good sense that if older adults process positive information in a particularly self-relevant manner, they might show a "positivity shift" in memory. It is possible that because of older adults' increased emphasis on emotion regulation (e.g., Carstensen et al., 1999; Gross et al., 1997), they may be prone to think about how positive things relate to their own life and to their own sense of self. It will be important for further research to examine the validity of this hypothesis by directly assessing the relation between self-referential processing and subsequent memory in young and older adults.

\section{Conclusions}

The present results emphasize that there are common regions that young and older adults recruit in order to remember emotional information. Young and older adults recruit the amygdala and the orbito-frontal cortex during the encoding of positive and negative information; they recruit the right fusiform gyrus preferentially during the encoding of negative information, and the left prefrontal and temporal regions disproportionately during the encoding of positive information. This general consistency in emotional memory processes aligns well with the overall preservation of the emotional memory enhancement effect with aging. However, age effects do emerge during the encoding of positive information. Older adults show a stronger correspondence than young adults between memory for positive information and activity in the medial prefrontal cortex, and in regions along the cingulate gyrus. Because these regions have been implicated in self-referential processing (Northoff et al., 2006; Macrae et al., 2004; Kelley et al., 2002), this finding suggests that the mnemonic enhancement that older adults (but not young adults) display for positive information may result from older adults' tendency to process positive information in reference to themselves.

\section{Acknowledgments}

This research was supported by the National Institutes of Health grant AG08411 (to D. L. S.) and by the National Science Foundation grant BCS-0542694 to E. A. K. Portions of this research were conducted while E. A. K. was a fellow of the American Federation for Aging Research.

Reprint requests should be sent to Elizabeth A. Kensinger, Department of Psychology, Boston College, McGuinn Hall, Rm. 510, 140 Commonwealth Avenue, Chestnut Hill, MA 02467, or via e-mail: elizabeth.kensinger@bc.edu.

\section{Notes}

1. Responses to items tested as similar exemplars are difficult to interpret. "Similar" responses to similar exemplars could reflect memory for visual detail (a participant could remember 
the details of the studied object and know that the tested exemplar did not match); however, a "similar" response also could reflect memory for only the general item type (a participant could remember that a particular type of object had been studied but have no memory for its visual details and therefore call it "similar"). A "new" response is also ambiguous: It could signify that the studied item was forgotten, but it also could be given if the participant remembered the studied item but did not apply the same verbal label to the tested exemplar. 2. The regions disproportionately active during older adults' encoding of positive items also tend to be the regions that are active in the "default" state, when participants do not need to be engaged in task-directed thought (e.g., Fox et al., 2005; Gusnard, Akbudak, Shulman, \& Raichle, 2001; Shulman et al., 1997). It has been proposed that there may be a link between these regions' roles in self-referential processing and their activity during these baseline (i.e., task-void) periods: When people are not given a specific task to perform, they often engage in self-referential thinking, including recollection of past experiences and simulations of future experiences (Schacter, Addis, \& Buckner, 2007). Older adults often show difficulty disengaging these regions during task performance, perhaps suggesting an increased tendency for older adults to continue self-referential processing even when it is not directly pertinent to task performance (e.g., Persson, Lustig, Nelson, \& ReuterLorenz, 2007; Grady, Springer, Hongwanishkul, McIntosh, \& Winocur, 2006; Lustig et al., 2003). It will be interesting for future research to examine whether this difficulty in disengagement may be associated with the increased importance that older adults place on emotion regulation goals (e.g., are the older adults who show the most difficulty disengaging selfreferential processes also those same individuals who put the greatest emphasis on emotional well-being).

\section{REFERENCES}

Bless, H., Clore, G. L., Schwarz, N., Golisano, V., Rabe, C., \& Wolk, M. (1996). Mood and the use of scripts: Does a happy mood really lead to mindlessness? Journal of Personality and Social Psychology, 71, 665-679.

Brett, M., Anton, J.-L., Valabregue, R., \& Poline, J.-B. (2002). Region of interest analysis using an SPM toolbox [abstract]. Presented at the 8th International Conference on Functional Mapping of the Human Brain, June 2-6, Sendai, Japan. Available on CD-ROM in Neuroimage 16.

Buchanan, T., \& Adolphs, R. (2002). The role of the human amygdala in Emotional Modulation of Long-Term Declarative Memory. In S. Moore \& M. Oaksford (Eds.), Emotional cognition: From brain to behavior. London, UK: John Benjamins.

Carstensen, L. L., Isaacowitz, D. M., \& Charles, S. T. (1999). Taking time seriously: A theory of socioemotional selectivity. American Psychologist. 54, 165-181.

Charles, S. T., Mather, M., \& Carstensen, L. L. (2003). Aging and emotional memory: The forgettable nature of negative images for older adults. Journal of Experimental Psvchologv: General, 132, 310-324.

Chow, T. W., \& Cummings, J. L. (2000). The amygdala and Alzheimer's disease. In J. P. Aggleton (Ed.), The amygdala: A functional analysis (pp. 656-680). Oxford, England: Oxford University Press.

Craik, F. I. M., Moroz, T. M., Moscovitch, M., Stuss, D. T., Winocur, G., Tulving, E., et al. (1999). In search of the self: A positron emission tomography study. Psychological Science, 10, 26-34.

D’Argembeau, A., Collette, F., Van der Linden, M., Laureys, S., Del Fiore, G., Degueldre, C., et al. (2005). Self-referential reflective activity and its relationship with rest: A PET study. Neuroimage, 25, 616-624.

Dale, A. M. (1999). Optimal experimental design for event-related fMRI. Human Brain Mapping, 8, 109-114.

Denburg, N. L., Buchanan, T. W., Tranel, D., \& Adolphs, R. (2003). Evidence for preserved emotional memory in normal older persons. Emotion, 3, 239-253.

Dobbins, I. G., \& Wagner, A. D. (2005). Domain-general and domain-sensitive prefrontal mechanisms for recollecting events and detecting novelty. Cerebral Cortex, 15, 1768-1778.

Fisher, R. A. (1950). Statistical methods for research workers. London: Oliver and Boyd.

Folstein, M. F., Folstein, S. E., \& McHugh, P. R. (1975). Mini-Mental State: A practical method for grading the state of patients for the clinician. Lournal of Psychiatric Research, 12, 189-198.

Fox, M. D., Snyder, A. Z., Vincent, J. L., Corbetta, M., Van Essen, D. C., \& Raichle, M. E. (2005). The human brain is intrinsically organized into dynamic, anticorrelated functional networks. Proceedings of the National Academy of Sciences. U.S.A., 102, 9673-9678.

Garoff, R. J., Slotnick, S. D., \& Schacter, D. L. (2005). The neural origins of specific and general memory: The role of the fusiform cortex. Neuropsychologia. 43, 847-859.

Gasper, K., \& Clore, G. L. (2002). Attending to the big picture: Mood and global versus local processing of visual information. Psvchological Science, 13, 34-40.

Grady, C. L., Springer, M. V., Hongwanishkul, D., McIntosh, A. R., \& Winocur, G. (2006). Age-related changes in brain activity across the adult lifespan. Journal of Cognitive Neuroscience, 18, 227-241.

Gross, J. J., Carstensen, L. L., Pasupathi, M., Tsai, J., Skorpen, C. G., \& Hsu, A. Y. C. (1997). Emotion and aging: Experience, expression, and control. Psychology and Aging, 12, 590-599.

Gunning-Dixon, F. M., Gur, R. C., Perkins, A. C., Schroeder, L., Turner, T., Turetsky, B. I., et al. (2003). Age-related differences in brain activation during emotional face processing. Neurobiology of Aging, 24, 285-295.

Gusnard, D. A., Akbudak, E., Shulman, G. L., \& Raichle, M. E. (2001). Medial prefrontal cortex and self-referential mental activity: Relation to a default mode of brain function. Proceedings of the National Academv of Sciences. U.S.A., 98, 4259-4264.

Gutchess, A. H., Kensinger, E. A., \& Schacter, D. L. (2007). Aging, self-referencing, and medial prefrontal cortex. Social Neuroscience, 2, 117-133.

Gutchess, A. H., Kensinger, E. A., Yoon, C., \& Schacter, D. L. (2007). Aging and the self-reference effect in memory. Memory 15, 822-837.

Gutchess, A. H., Welsh, R. C., Hedded, T., Bangert, A., Minear, M., Liu, L. L., et al. (2005). Aging and the neural correlates of successful picture encoding: Frontal activations compensate for decreased medial-temporal activity. Journal of Cognitive Neuroscience, 17, 84-96.

Hamann, S. B. (2001). Cognitive and neural mechanisms of emotional memory. Trends in Cognitive Sciences, 5, 394-400.

Kelley, W. M., Macrae, C. N., Wyland, C. L., Caglar, S., Inati, S., \& Heatherton, T. F. (2002). Finding the self? An event-related fMRI study. Journal of Cognitive Neuroscience, 14, 785-794.

Kensinger, E. A. (2007). How negative emotion affects memory accuracy: Behavioral and neuroimaging evidence. Current Directions in Psvchological Science. 16, 213-218.

Kensinger, E. A., Brierley, B., Medford, N., Growdon, J. H., \& Corkin, S. (2002). Effects of normal aging and Alzheimer's disease on emotional memory. Emotion, 2, 118-134. 
Kensinger, E. A., \& Corkin, S. (2003). Neural changes in ageing. In L. Nadel (Ed.), Encyclopedia of cognitive science. London: Macmillan.

Kensinger, E. A., Garoff-Eaton, R. J., \& Schacter, D. L. (2006). Memory for specific visual details can be enhanced by negative arousing content. Journal of Memory and Language, 54, 99-112.

Kensinger, E. A., Garoff-Eaton, R. J., \& Schacter, D. L. (2007a). Effects of emotion on memory specificity: Memory trade-offs elicited by negative visually arousing stimuli. Journal of Memorv and Language, 56, 575-591.

Kensinger, E. A., Garoff-Eaton, R. J., \& Schacter, D. L. (2007b). Effects of emotion on memory specificity in young and older adults. Journal of Gerontology, 62, P208-P215.

Kensinger, E. A., Garoff-Eaton, R. J., \& Schacter, D. L. (2007c). How negative emotion enhances the visual specificity of a memory. Journal of Cognitive Neuroscience. 19, 1872-1887.

Kensinger, E. A., O’Brien, J., Swanberg, K., Garoff-Eaton, R. J., \& Schacter, D. L. (2007). The effects of emotional content on reality-monitoring performance in young and older adults. Psychology and Aging, 22, 752-764.

Kensinger, E. A., \& Schacter, D. L. (2006). When the Red Sox shocked the Yankees: Comparing negative and positive memories. Psychonomic Bulletin E Review, 13, 757-763.

Koutstaal, W., Wagner, A. D., Rotte, M., Maril, A., Buckner, R. L., \& Schacter, D. L. (2001). Perceptual specificity in visual object priming: fMRI evidence for a laterality difference in fusiform cortex. Neuropsychologia. 39, 184-199.

LaBar, K. S., \& Cabeza, R. (2006). Cognitive neuroscience of emotional memory. Nature Reviews Neuroscience, 7, 54-56.

Labouvie-Vief, G. (1982). Growth and aging in life span perspective. Human Development, 25, 65-79.

Lazar, N. A., Luna, B., Sweeney, J. A., \& Eddy, W. F. (2002). Combining brains: A survey of methods for statistical pooling of information. Neuroimage, 16, 538-550.

Levine, L. J., \& Bluck, S. (2004). Painting with broad strokes: Happiness and the malleability of event memory. Cognition and Emotion, 18, 559-574.

Lustig, C., Snyder, A. Z., Bhakta, M., O’Brien, K., McAvoy, M., Raichle, M. E., et al. (2003). Functional deactivations: Change with age and dementia of the Alzheimer type. Proceedings of the National Academv of Sciences. U.S.A., 100, 504-509.

Macrae, C. N., Moran, J. M., Heatherton, T. F., Banfield, J. F., \& Kelley, W. M. (2004). Medial prefrontal activity predicts memory for self. Cerebral Cortex, 14, 647-654.

Mather, M. (2006). Why memories may become more positive as people age. In B. Uttl, N. Ohta, \& A. L. Siegenthaler (Eds.), Memory and emotion (pp. 135-159). Malden, MA: Blackwell Press.

Mather, M., Canli, T., English, T., Whitfield, S., Wais, P., Ochsner, K., et al. (2004). Amygdala responses to emotionally valenced stimuli in older and younger adults. Psychological Science, 15, 259-263.

Mather, M., \& Carstensen, L. L. (2005). Aging and motivated cognition: The positivity effect in attention and memory. Trends in Cognitive Sciences, 9, 296-502.

Mather, M., \& Knight, M. (2005). Goal-directed memory: The role of cognitive control in older adults' emotional memory. Psychology and Aging, 20, 554-570.

Mueller, J. H., Wonderlich, S., \& Dugan, K. (1986). Self-referent processing of age-specific material. Psvchologv and Aging 1, 293-299.

Northoff, G., Heinzel, A., de Greck, M., Bermpohl, F., Dobrowolny, H., \& Panksepp, J. (2006). Self-referential processing in our brain-A meta-analysis of imaging studies on the self. Neuroimage, 31, 440-457.
Ochsner, K. N. (2000). Are affective events richly "remembered" or simply familiar? The experience and process of recognizing feelings past. Journal of Experimental Psychologv: General, 129, 242-261.

Paller, K. A., \& Wagner, A. D. (2002). Observing the transformation of experience into memory. Trends in Cognitive Sciences, 6, 93-102.

Persson, J., Lustig, C., Nelson, J. K., \& Reuter-Lorenz, P. A. (2007). Age differences in deactivation: A link to cognitive control? Journal of Cognitive Neuroscience, 19, 1021-1032.

Poldrack, R. A., Wagner, A. D., Prull, M. W., Desmond, J. E., Glover, G. H., \& Gabrieli, J. D. E. (1999). Functional specialization for semantic and phonological processing in the left inferior prefrontal cortex. Neuroimage, 10, 15-35.

Reisberg, D., \& Heuer, F. (2004). Remembering emotional events. In D. Reisberg \& P. Hertel (Eds.), Memory and emotion (pp. 3-41). New York: Oxford University Press.

Rogers, T. B., Kuiper, N. A., \& Kirker, W. S. (1977). Self-reference and the encoding of personal information. Journal of Personality and Social Psvchology, 35, 677-688.

Salat, D. H., Buckner, R. L., Snyder, A. Z., Greve, D. N., Desikan, R. S. R., Busa, E., et al. (2004). Thinning of the cerebral cortex in aging. Cerebral Cortex, 14, 721-730.

Salat, D. H., Kaye, J. A., \& Janowsky, J. S. (2001). Selective preservation and degeneration within the prefrontal cortex in aging and Alzheimer's disease. Archives of Neurology, 58, 1403-1408.

Schacter, D. L., Addis, D. R., \& Buckner, R. L. (2007) Remembering the past to imagine the future: The prospective brain. Nature Reviews Neuroscience, 8, 657-661.

Shulman, G. L., Fiez, J. A., Corbetta, M., Buckner, R. L., Miezin, F. M., Raichle, M. E., et al. (1997). Common blood flow changes across visual tasks: II. Decreases in cerebral cortex. Journal of Cognitive Neuroscience, 9, 648-663.

Storbeck, J., \& Clore, G. L. (2005). With sadness comes accuracy; with happiness, false memory: Mood and the false memory effect. Psvchological Science, 16, 785-791.

Symons, C. S., \& Johnson, B. T. (1997). The self-reference effect in memory: A meta-analysis. Psvchological Bulletin 121, 371-394.

Talairach, J., \& Tournoux, P. (1988). Co-planar stereotaxic atlas of the buman brain. New York: Thieme.

Tessitore, A., Hariri, A. R., Fera, F., Smith, W. G., Das, S., Weinberger, D. R., et al. (2005). Functional changes in the activity of brain regions underlying emotion processing in the elderly. Psychiatry Research, 139, 9-18.

Thomas, R. C., \& Hasher, L. (2006). The influence of emotional valence on age differences in early processing and memory. Psychology and Aging, 21, 821-825.

Tisserand, D. J., Visser, P. J., van Boxtel, M. P. J., \& Jolles, J. (2000). The relation between global and limbic brain volumes on MRI and cognitive performance in healthy individuals across the age range. Neurobiology of Aging. 21, 569-576.

Wechsler, D. (1997). Technical manual for the Wechsler Adult Intelligence and Memory Scale-Third Edition. New York: The Psychological Corporation.

Williams, L. M., Brown, K. J., Palmer, D., Liddell, B. J., Kemp, A. H., Olivieri, G., et al. (2006). The mellow years? Neural basis of improving emotional stability over age. Iournal of Neuroscience, 26, 6422-6430.

Wright, C. I., Wedig, M. M., Williams, D., Rauch, S. L., \& Albert, M. S. (2006). Novel fearful faces activate the amygdala in healthy young and elderly adults. Neurobiologv of Aging. 27, 361-374. 